
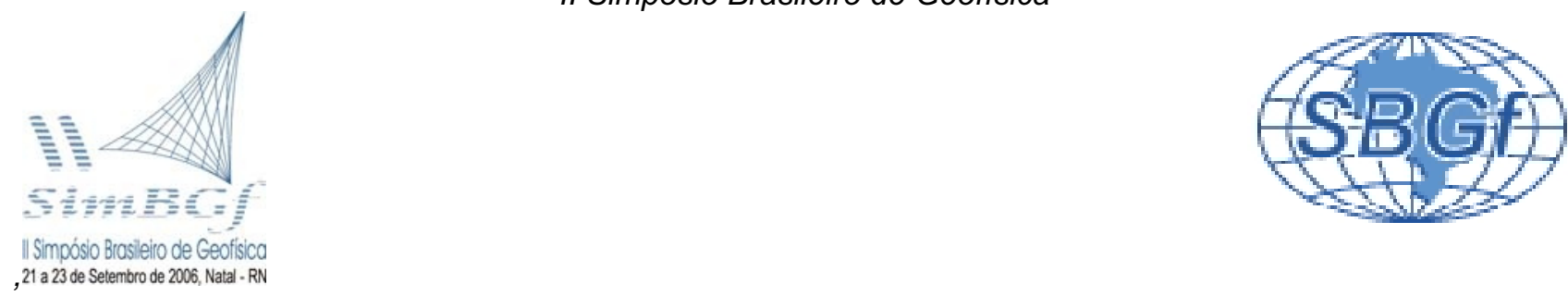

\title{
Avaliação da Poluição de Aqüíferos e de suas Zonas Vadosas Usando Medidas Geoelétricas em Poços e em Perfilagens Superficiais
}

Olivar A. Lima de Lima e Patrícia de A. Pereira

Copyright 2006, SBGf-Sociedade Brasileira de Geofísica

Este texto foi preparado para a apresentação no II Simpósio de Geofísica da Sociedade Brasileira de Geofísica, Natal, 21-23 de setembro de 2006. Seu conteúdo foi revisado pela Comissão Tecno-científica do II SR-SBGf mas não necessariamente representa a opinião da SBGf ou de seus associados. E proibida a reprodução total ou

\section{Abstract}

Apparent resistivity and chargeability were measured as a function of depth in multi-electrode wells, and as a function of electrode spacing in double semiSchlumberger surface soundings. A multi-electrode well is a special monitoring well where we externally install copper electrodes as thin metallic rings, spaced by $0.50 \mathrm{~m}$ along its entire filter and casing length. Two-side semiSchlumberger soundings expanded up to $200 \mathrm{~m} \mathrm{AB/2}$ spacing and with centers spaced by $50 \mathrm{~m}$ along transverse profiles were inverted using $1 \mathrm{D}$ and $2 \mathrm{D}$ models. Both techniques were used to study the groundwater contamination related to adjacent landfill and industrial disposal sites in Alagoinhas county, Bahia. The electrical measurements performed at the earth surface and within wells, were used both to characterize the plume and to estimate changes in water saturation and shalyness above the water table and throughout the upper section of the Marizal-São Sebastião aquifer system.

\section{Introdução}

Aterros sanitários, pela própria natureza, distribuição espacial e temporal e modos de construção e operação, são obras de engenharia com elevados graus de risco para a degradação dos solos, dos recursos hídricos e da própria saúde humana (MacFarlane et al., 1983, Kjeldsen et al., 1998, Acworth and Jorstad, 2006). Os riscos reais e potenciais da operação de um aterro constituem aspectos importantes na avaliação de seus efeitos sobre a qualidade do ambiente. As questões mais preocupantes são: (i) como detectar e avaliar a extensão e a severidade de uma contaminação subterrânea? (ii) como avaliar seus efeitos sobre o ambiente e a saúde humana? Neste contexto, são de grande importância as investigações geológicas, geofísicas e geobiológicas dos ambientes superficiais e subsuperfíciais.

O sitio do aterro de Alagoinhas se localiza próximo a Rodovia BR-101, a cerca de 12 km de distância da sede municipal (Fig. 1). Parte desta área foi anteriormente usada para dispor, sem preparativos e a céu aberto, os resíduos sólidos produzidos no município. Em adição, um grande curtume está implantado, desde 1979, próximo a porção sudoeste do depósito abandonado.

Um espesso aqüífero freático subjaz quase toda a área do município de Alagoinhas. Este potente aqüífero constitui a principal fonte de água que supre as populações humanas $e$ as atividades industriais $e$ agrícolas em toda sua região de ocorrência. O uso local da terra em torno do aterro está afetando severamente este aqüífero, bem como a rede de drenagem das águas superficiais. Durante o ano de 2004, um levantamento geofísico elétrico, realizado pelo CPGG/UFBA, permitiu delinear uma extensiva pluma de contaminação cobrindo mais de $1,5 \mathrm{~km}^{2}$ abaixo do nível freático (Fig.2). As principais características dessa pluma são: baixo $\mathrm{pH}$ e baixas resistividade e polarizibilidade elétricas em função da elevada carga de sais dissolvidos (Pereira, 2004).

Visando adequar e integrar metodologias geofísicas apropriadas para detectar e monitorar plumas contaminantes estamos desenvolvendo no CPGG/UFBA novas técnicas de aquisição, de superfície e de poço, que tem se mostrado úteis para quantificar um balanço hídrico através no sistema zona vadosa-aqüífero, assim como para melhor esboçar os limites laterais de zonas contaminadas. Nesse sentido, desenvolvemos e testamos duas técnicas de alta resolução, uma de superfície e outra de poço, que são muito sensitivas a variações elétricas laterais. Alguns resultados obtidos com essas novas estratégias são apresentados no presente trabalho.

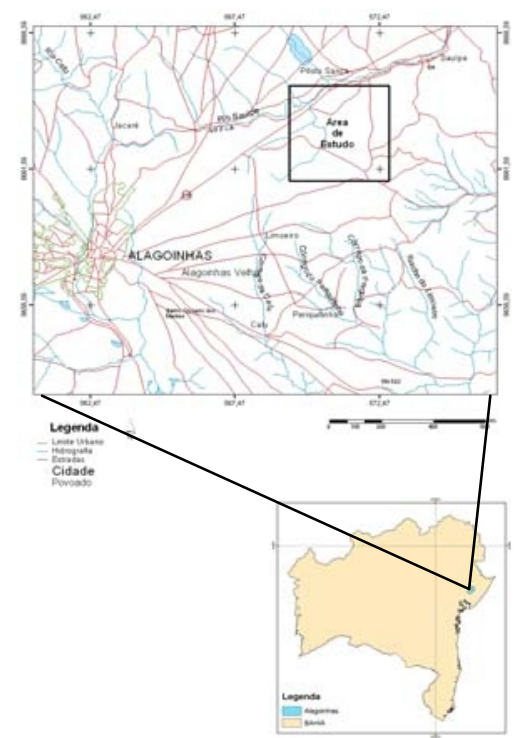

Figura 1. Mapa de localização e acesso a área de estudo. 


\section{Metodologia}

Após concluída a primeira fase do projeto Alagoinhas foram construídos três poços especiais de monitoramento localizados no interior ou próximo da pluma delineada. $\mathrm{O}$ primeiro localizado diretamente acima do núcleo da pluma foi perfurado até $20 \mathrm{~m}$ de profundidade; o segundo também com $20 \mathrm{~m}$ de profundidade se situou na borda oriental do aterro visando monitorar a zona de transição da pluma naquele local; o terceiro com $30 \mathrm{~m}$ de profundidade, também locado para monitorar a zona de transição, foi perfurado a $500 \mathrm{~m}$ a oeste do aterro, próximo a um bosque de eucaliptos (Fig. 3). Estes poços, perfurados em 8" de diâmetro, foram revestidos com tubos e filtros de PVC rígido de 4" de diâmetro. Externamente aos revestimentos foram instalados eletrodos anelares $(2 \mathrm{~mm}$ de espessura $\times 1 \mathrm{~cm}$ de largura) equidistantes entre si de $0,5 \mathrm{~m}$, e diretamente conectados à superfície por cabos individuais devidamente numerados. O conjunto dos cabos foi preso internamente ao tubo de modo a permitir a passagem de uma bomba hidráulica de 3" para fazer o poço produzir (fotos 1 e 2).
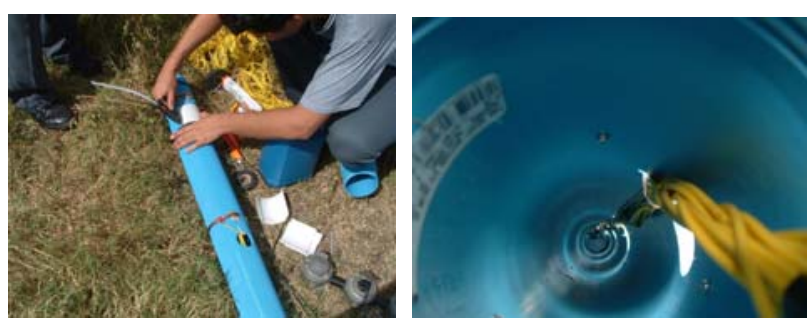

Fotos 1 e 2. Disposição de eletrodos e cabos no revestimento dos poços.

Os eletrodos anelares foram combinados em arranjos normais, para perfilar os poços com 6 distâncias laterais de investigação variando de 0,5 a $3,0 \mathrm{~m}$. Cada poço foi perfilado duas vezes nas seguintes condições: (i) a primeira, imediatamente após a completação e desenvolvimento dos poços com o compressor da sonda; (ii) a segunda, após um desenvovimento adicional com bomba hidráulica bombeando durante períodos de 24 horas. As perfilagens foram executadas com equipamento Syscal R2, com medições simultaneas da resistividade e da cargabilidade elétricas.

Para melhorar a definição da pluma realizamos também perfilagens superficiais de IP-resistividade usando sondagens múltiplas alinhadas e equi-espaçadas, com arranjos semi-Schlumberger lateralmente alternados, em relação ao eletrodo de corrente ativo. Para cada posição de fonte ativa, duas sondagens foram realizadas: uma com o dipolo de medição movendo-se para a direita da fonte e outra em que o dipolo se move para a esquerda. As fontes foram deslocadas no sentido de descrever duas sondagens elétricas no centro de cada dipolo de medição.

Para uma terra horizontalmente estratificada, é fácil mostrar que a função resistividade aparente computada para os dois arranjos laterais semi-Schlumberger, tem o mesmo valor, igual aquele obtido para o arranjo Schlumberger completo.

Cinco linhas de perfilagem iniciadas no poço de monitoramento PM-5, localizado sobre o antigo depósito de lixo, foram levantadas para melhor delinear os limites laterais da pluma contaminante em sua extensão atual em direção a área do aterro.

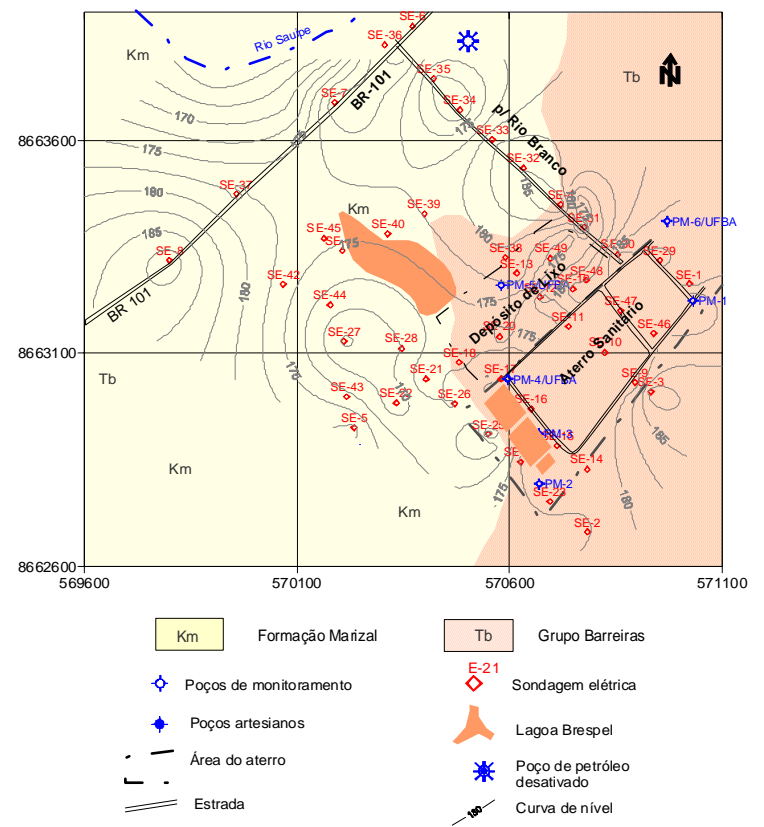

Figura 3. Mapa geológico e de localização das fontes de poluição.

\section{Resultados e Discussão}

$\mathrm{Na}$ interpretação quantitativa das multi-perfilagens foram adotadas as seguintes suposições: (i) a aplicabilidade do modelo proposto por Lima et al. (2005) para descrever a condutividade elétrica de arenitos argilosos; (ii) as resistividades elétricas do fluido, na zona vadosa e no aqüífero, tem o mesmo valor que àqueles observados nas águas produzidas nos poços; (iii) a argila presente nos materiais arenosos de cobertura e nos arenitos é do tipo caulinita; e (iv) os valores observados com os maiores espaçamentos AMs correspondem, com boa aproximação, a resistividade verdadeira da formação.

$\mathrm{Na}$ Figura 4, para ilustrar os procedimentos de interpretação, são mostrados os perfis de IP e de resistividade observados no poço $\mathrm{PM}-5$, na segunda coleta de dados. Os perfis de resistividade indicam que o material ali depositado se encontra parcialmente saturado com lixiviado de elevada condutividade elétrica. Os resultados interpretados para a distribuição da saturação e da argilosidade estão indicados no gráfico da direita. A saturação está elevada (acima de 90\%), na porção superior do depósito, devido à alta infiltração de águas de chuvas, abundantes no período em que as perfilagens foram executadas. Ela decai até um mínimo de $65 \%$ no intervalo de 10,4 a 13,5 m de profundidade, aumentando gradativamente até $15,4 \mathrm{~m}$ quando foi alcançado o nível 
freático $\left(S_{w}=1\right)$. O perfil de argilosidade guarda um certo paralelo com o de saturação, sendo ela mais elevada na parte da cobertura e na parte superior do aqüífero, onde cresce uniformemente com a profundidade. Note que a posição do nível estático da água subterrânea não está claramente definida nos perfis de resistividade, mas é bem delineada nas curvas de IP, em conformidade com observações experimentais de vários autores (Vacquier et al., 1957; Parkomenko, 1967).

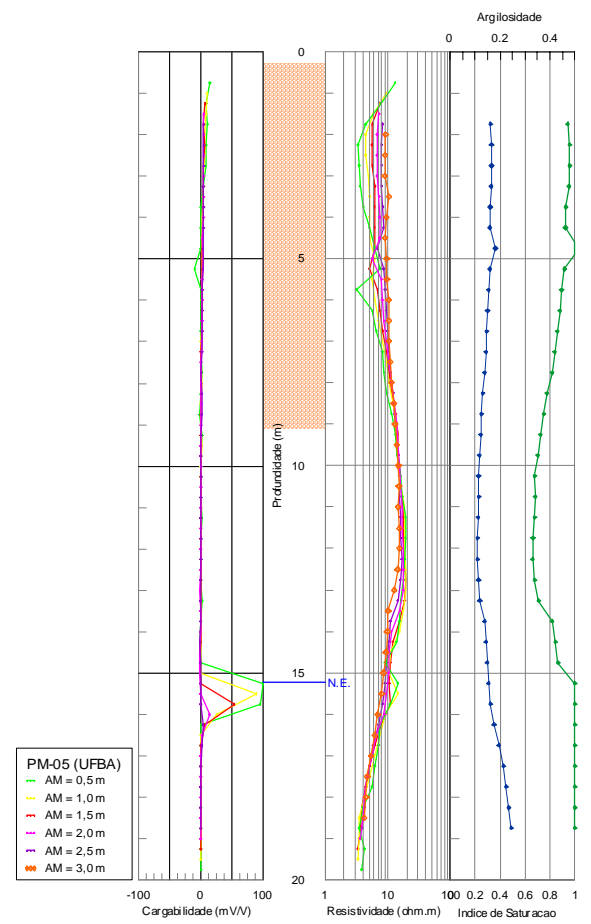

Figura 4. Perfis de IP-resistividade e indice de saturação de água interpretados para o poço de monitoramento PM-5.

Como resultado das perfilagens superficiais, os gráficos das figuras 5 e 6 ilustram as imagens de IP e resistividade obtidas na linha NW com as duas configurações de aquisição propostas. As imagens obtidas com o dipolo de potencial caminhando para a direita mostram duas zonas laterais distintas: uma condutiva e de baixo IP à esquerda; e outra resistiva à direita, na qual a resistividade aparente está sempre acima de $400 \mathrm{ohm}$.m. Na porção resistiva, a resistividade do aqüífero diminui sensivelmente com a profundidade. Como a polarizibilidade cresce no mesmo sentido, inferese um aumento da argilosidade com a profundidade na direção do perfil. A transição entre as duas zonas identificadas é estreita, com largura inferior a $50 \mathrm{~m}$.

Quando o dipolo é deslocado para a esquerda, embora os resultados sejam bem distintos, é possível observar que a zona condutiva fica melhor definida e coincide com valores baixos e até negativos de IP, principalmente no trecho mais condutivo da anomalia. A zona de transição continua estreita e não é mais perceptível o crescimento da argilosidade com a profundidade.
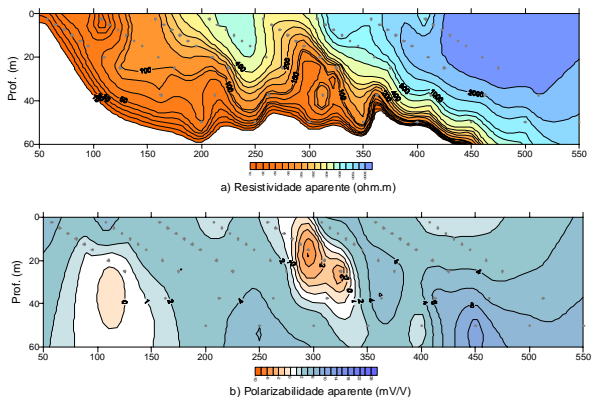

Figura 5. Seções geoelétricas construídas para o arranjo semi-Schlumberger, com dipolo se deslocando para a direita.
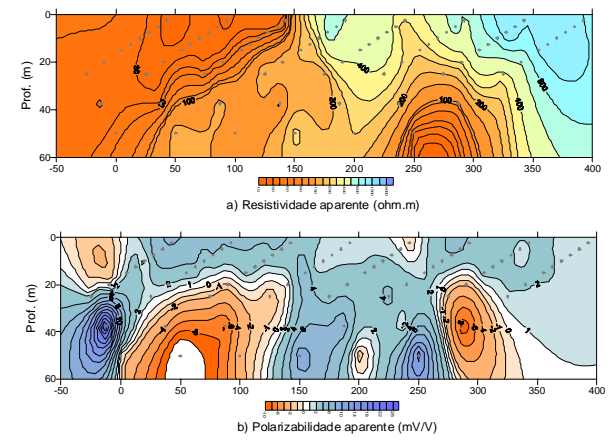

Figura 6. Seções geoelétricas construídas para o arranjo semi-Schlumberger, com dipolo se deslocando para a esquerda.
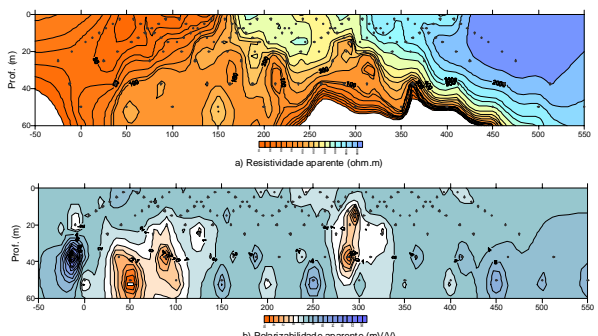

Figura 7. Seções geoelétricas obtidas a partir da interpolação das seções de dipolo para direita e para esquerda.

A figura 7 ilustra as imagens obtidas com a interpolação das duas seções superpostas. Duas zonas são claramente delineadas: à zona condutora se associa uma baixa (ou negativa) polarizibilidade em função da alta concentração de sais dissolvidos; o aqüífero, na parte norte, é revelado com aumento crescente no conteúdo de argilas com a profundidade, em conformidade com as indicações dos multi-perfis dos poços de monitoramento. A zona transicional, começa com inclinação de sul para norte e se verticaliza com o aumento da profundidade. Esses resultados são confirmados pela inversão unidimensional das curvas de sondagens do perfil. Os mesmos dados estão sendo invertidos com modelos geoelétricos bidimensionais. 


\section{Conclusões}

Os resultados geofísicos descritos neste trabalho reforçam claramente a presença de uma extensiva contaminação do sistema aqüífero regional, delineadas como anomalias de IP-resistividade em seções geoelétricas transversais. Esta contaminação é atribuída à invasão de lixiviados provenientes de dois depósitos de lixo e efluentes de um curtume, devido a inexistência ou imperfeição dos sistemas de proteção em suas bases.

A pluma condutiva consiste de um núcleo central salino e denso, que se extende até $45 \mathrm{~m}$ de profundidade, envolvido por uma auréola de transição suspensa sobre a água subterrânea nativa, e que se desloca em direção ao curso do rio Sauípe. A porção mais ativa e concentrada da pluma ocorre abaixo da área do antigo depósito de lixo e das lagoas de disposição de efluentes do curtume, e tem resistividade verdadeira em torno de 4 ohm.m.

As técnicas de poços multi-eletrodos e da perfilagem superficial semi-Schlumberger utilizadas neste trabalho podem ser avaliadas como de emprego vantajoso em relação as técnicas convencionais de monitoramento de áreas contaminadas, pelos seguintes motivos:

(1) Poços multi-eletrodos e poços convencionais de monitoramento servem basicamente para se fazer um controle espaço-temporal da qualidade da água de um aqüífero. O aumento no custo de implantação de um poço multi-eletrodo, representado pelo custo dos eletrodos, dos cabos de conexão e do material de isolamento (estimado em cerca de $\mathrm{R} \$ 500,00$ para um poço de $20 \mathrm{~m}$ de profundidade) é sobejamente compensado pelos seguintes méritos adicionais: (i) permitem fazer repetidas investigações sobre as características elétricas da água e do material geológico da subsuperfície, à diferentes distâncias de penetração a partir da parede do furo; (ii) facilitam a investigação das condições hidráulicas da infiltração de água e/ou poluentes para o aqüífero desde a superfície do solo até abaixo do nível freático, passando pela zona vadosa; (iii) com as observações acima apontadas se pode descrever as variações de porosidade, de argilosidade e de conteúdo de água no subsolo, ao longo da extensão vertical do poço; (iv) qualquer equipamento de exploração geofísica elétrica pode ser aplicado nessas avaliações;

(2) As técnicas convencionais de sondagem e de perfilagem elétricas têm tido amplo sucesso no delineamento de zonas poluídas de aqüíferos. Todavia, na maioria dos casos essas plumas contaminantes possuem limites irregulares e heterogêneos, dificultando seu preciso posicionamento espacial, em função do afastamento da condição de sub-horizontalidade e homogeneidade subentendida nos esquemas de interpretação unidimensional. A técnica de se efetuar, simultâneamente, dois conjuntos de dados de multiperfilagem usando arranjos semi-Schlumberger, além de aumentar a densidade de informações sobre a condições geoelétricas da sub-superficie, realça melhor as interfaces laterais entre a pluma e o aqüífero em sua condição natural.

\section{Agradecimentos}

Os autores agradecem ao Programa PROSAB da FINEP e a Prefeitura Municipal de Alagoinhas pelo apoio a realização do presente trabalho. Ao CPGG/UFBA pelo ambiente favorável e o suporte ao projeto. Ao CNPq pelo financiamento de bolsa de produtividade em pesquisa de Olivar Lima e de doutorado de Patrícia Andrade.

\section{Referências}

Lima, O. A. L., Clennell, M. B., Nery, G. G. e Sri Niwas, 2005. A volumetric approach for the resistivity response of freshwater shaly sandstones. Geophysics. 70(1), F1F10.

Parkomenko, E. I., 1967. Electrical Properties of Rocks: Plenum Press Inc., New York.

Pereira, P. A., 2004. Alterações ambientais causadas por depósito de lixo urbano e curtume no município de Alagoinhas, Bahia. Dissertação de Mestrado em Geoquímica, Universidade Federal da Bahia.

Vacquier V., Holmes, C. R., Kintzinger, P. R. \& Lavergne, M., 1957. Prospecting for ground water by induced electrical polarization: Gephisics 22(3), 660-687. 


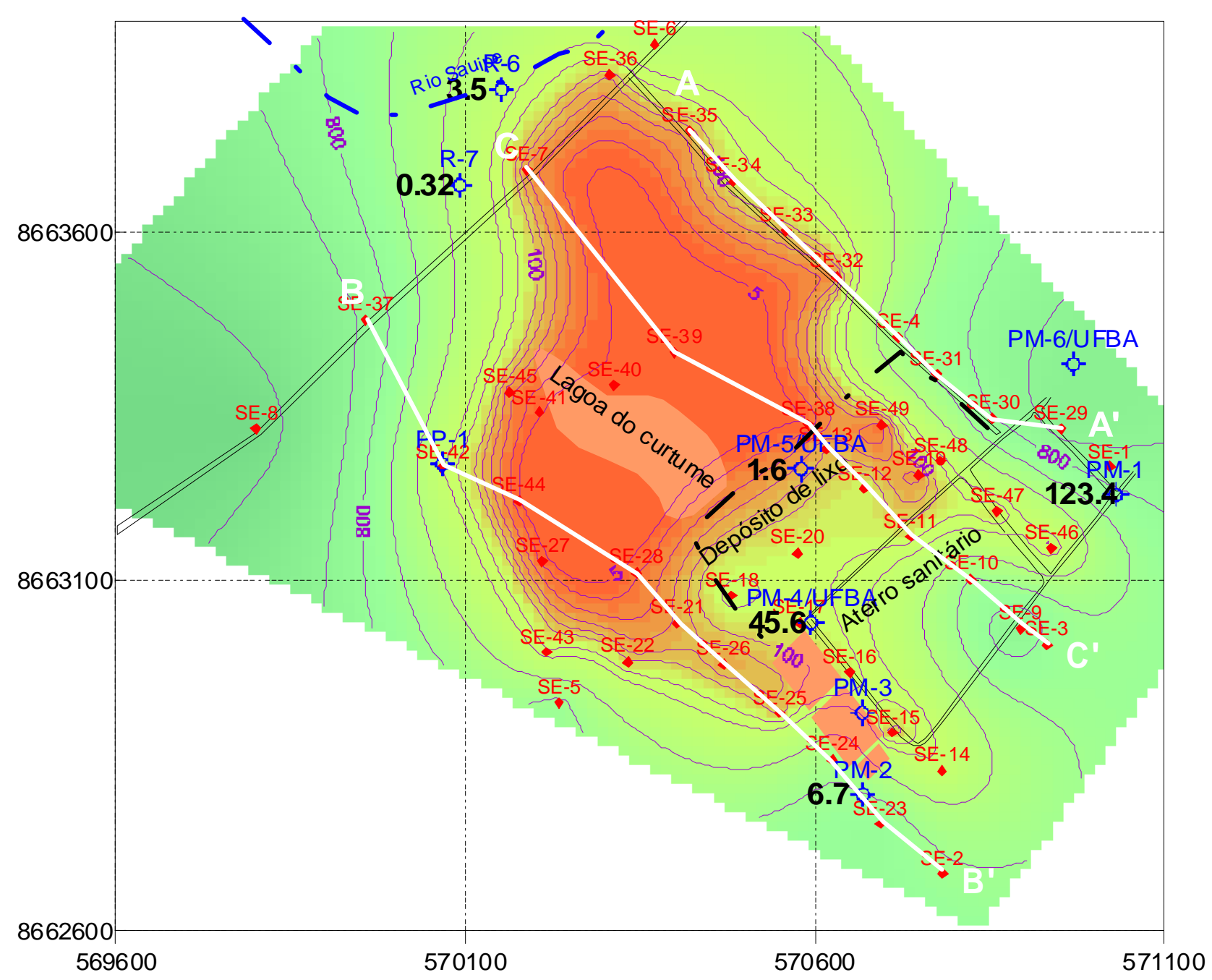

Figura 2. Resistividade verdadeira no topo da zona saturada do aqüífero. 